\title{
Evaluation of the Mechanical Properties of Shafts Manufactured With 3D Printing for Different Inclinations of the Fused Deposition Layers
}

\author{
Holger Cacua, César Peña* and Bladimir Ramon \\ Department of Mechanics, Mechatronics and Industrial Engineering, University of Pamplona, Pamplona, Colombia; \\ holger.cacua@unipamplona.edu.co,cesarapc@unipamplona.edu.co,hbladimir@unipamplona.edu.co
}

\begin{abstract}
Objective: The Fused Deposition Modeling (FDM) has become a manufacturing technique in less time and at low cost. However, this process is influenced by the anisotropy of the pieces, because their resistance depends on the orientation of the deposited threads. In this paper, it is proposed to evaluate the mechanical strength of cylindrical shafts made of Polylactide (PLA), aiming to correlate the flexural behaviour of the material with different inclinations on the layers and improving the efficiency of the parts manufactured by this technique in operation. Materials and Methods: An experimental design was made where cylinders with different angles of inclination were manufactured in order to examine the mechanical flexural properties and determine the degree of affectation when the orientation of the fused deposition layers is modified. Findings: According to the results of mechanical flexural properties, variations in the tests calculated parameters are evidenced as a result of the anisotropic nature that generates the deposition's assembly orientation in the direction of the applied force. Conclusion: The failure analysis of the cylindrical shafts by means of fractography, shows important characteristics in correspondence to applied load, mainly due to the increase of ductility in PLA $50^{\circ}$ system, as a consequence of energy absorption by the material from the beginning and spreading of the crack.
\end{abstract}

Keywords: 3D Printing, Flex, Fracture, Inclination

\section{Introduction}

Fused Deposition Modeling (FDM) technology, was invented in 1988 by Scott Cump, initially it was an alternative for the manufacture of pieces replicas in order to test designs before starting production in series through other processes. It was also useful in the development of architectural models for its versatility and precision, with the passage of time FDM evolved and has positioned itself in different sectors.

Additive Manufacturing ( $\mathrm{AM}$ ) or $3 \mathrm{D}$ printing is a process for manufacturing parts, from different materials such as metals, polymers ${ }^{1}$ compounds ${ }^{2}$. The food industry uses this manufacturing technique to obtain chocolatebased products ${ }^{3}$, likewise, oat and pasta fibbers make use of $3 \mathrm{D}$ printing to prepare different foods ${ }^{4}$.
3D printing of polymers can be done using three techniques. The first method is known as stereolithography (STA), where photopolymer in liquid state is subjected to ultraviolet radiation to solidify and form a piece with the desired geometry. The second process consists of laser sintering (SLS), here the polymer is pulverized and subjected to the heat of a high powered laser beam allowing the fusion of the particles and the production of $3 \mathrm{D}$ parts. Finally, the FDM method, in which heat is applied to the polymer until the melting point and then deposited on a platform (hot bed), adding several layers to obtain solid elements.

This manufacturing technique has numerous fields of application; in 2017 a web tool was created to manufacture topographic designs with 3D printing 5 On the other hand, research has reported its biomedical 
applications where additive manufacturing has been the method for the manufacture of biocompatible prostheses for the human body. FDM was used to perform a cranial reconstruction procedure ${ }^{6}$. Also, an implantable micro-controller was developed by means of this technique to evaluate the neuronal activity of fish ${ }^{\mathrm{T}}$. Projects have been developed to replace the use of animals in laboratory practices ${ }^{-}$through additive manufacturing; cheaper hand prostheses were produced with shorter manufacturing times? ${ }^{9}$. In educational institutions such as the University of Pamplona, the need for 3D prototyping equipment encourages the production of a $3 \mathrm{D}$ print under the focus of the Quality Function Development (QFD) methodology ${ }^{10}$.

One problem with FDM technology is the anisotropy (the orientation of the layers gives it greater resistance in certain directions $)^{11}$, as it is reflected in the production of shafts. These elements have greater resistance to torsion and tension stress than to bending, the latter being a functional property for these applications. Studies indicate that there are parameters such as layer height, printing speed, type of fabric, type of material, density of the piece among others, which influence the resistance of these objects ${ }^{12}$.

In this investigation, it is proposed to evaluate the mechanical strength of cylindrical shafts made of PLA, aiming to correlate the flexural behaviour of the material with different inclinations on the layers and improving the efficiency of the parts manufactured by this technique in operation. For this purpose, cylinders with angles different from $90^{\circ}$ were manufactured with the purpose of examining the mechanical bending properties and determining the degree of affectation when the orientation of the fused layers is modified.

\section{Materials and Methods}

\subsection{Materials}

In the present study, a polymer called polylactide or (PLA) was used for the production of the shafts. PLA is a biodegradable material obtained from renewable resources such as corn. Among the most relevant advantages, the degree of biocompatibility with the tissues of the human body is deliberated $\underline{13}$.

The properties of the PLA according to the manufacturer, Ultimaker can be seen in Table 1.
Table 1. Mechanical properties of the PLA

\begin{tabular}{|l|c|c|}
\hline \multicolumn{3}{|c|}{ PLA Mechanical Properties } \\
\hline Elastic module & $3,3-3,6$ & $\mathrm{Gpa}$ \\
\hline Elastic limit & $55-72$ & $\mathrm{Mpa}$ \\
\hline Tensile strength & $47-70$ & $\mathrm{Mpa}$ \\
\hline \% Elongation & $2,5-6$ & $\%$ Strain \\
\hline Compression module & $3,3-3,5$ & $\mathrm{Gpa}$ \\
\hline Compression force & $66-86,4$ & $\mathrm{Mpa}$ \\
\hline Flexure force & 103 & $\mathrm{Mpa}$ \\
\hline Flexure module & $3,1-3,6$ & $\mathrm{Gpa}$ \\
\hline Cutting module & $5,7-6,3$ & $\mathrm{GPa}$ \\
\hline Hardness-vickers & $17-22$ & $\mathrm{HV}$ \\
\hline
\end{tabular}

\subsection{Shaft fabrication}

The Shafts' design was carried out according to the dimensions stipulated in the ASTM 790 standard. Subsequently, the processes of Computer-Aided Manufacturing (CAM) were carried out to generate the extrusion routes according to the different manufacturing parameters proposed (type of pattern, temperature, speeds, among others), as mentioned in (Table 2). Figure 1 shows the changes of inclination of the deposition layers in regards to a vertical axis, where $\alpha$ angle corresponds to $90^{\circ}$ and $\beta$ angle to $50^{\circ}$.

In (Figure 2), a process elaboration simulation of vertical specimens is shown, displaying the construction of layers generated by means of concentric circles (Figure 2a). The layers accumulate vertically up until the cylindrical specimens are constructed (Figure 2, b and c). Using this technique it is evidenced that the angle between the printing layer and horizontal plane is $0^{\circ}$ degrees.

According to the proposed hypothesis, a new generation of printing routes was designed where the layers have an angle of less than $90^{\circ}$ degrees in respect to the

Table 2. Printing parameters

\begin{tabular}{|l|c|c|}
\hline \multicolumn{1}{|c|}{ Parameter } & Value & Unit \\
\hline Temperature extruder & 205 & ${ }^{\circ} \mathrm{C}$ \\
\hline Temperature bed & 70 & ${ }^{\circ} \mathrm{C}$ \\
\hline Layer height & 0,2 & $\mathrm{Mm}$ \\
\hline Internal perimeters & 7 & $\mathrm{UNI}$ \\
\hline External perimeters & 15 & $\mathrm{UNI}$ \\
\hline Bottom fill pattern & Concentric & \\
\hline Density & 40 & $\%$ \\
\hline Printing Speed & 80 & $\mathrm{~mm} / \mathrm{s}$ \\
\hline
\end{tabular}



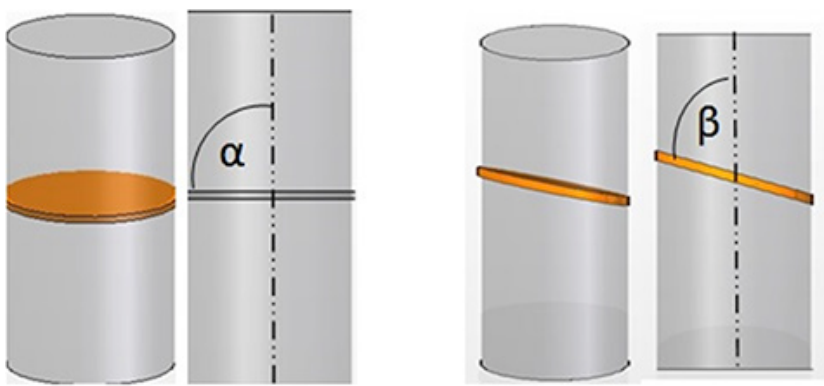

Figure 1. Vertical specimen free-body diagram.

horizontal plane. Figure 3 a shows the routes of as haft with an inclination of $50^{\circ}$ degrees in regards to the plane in question; therefore, layers are formed into ellipses, which would improve the union area between the surfaces. It is worth mentioning that with this new inclination during the manufacturing process, it becomes necessary to use support material to keep the section the falling (Figure 3 $(\mathrm{b}$ and $\mathrm{c})$ ).
With exception to the angle of inclination, all parameters used during manufacturing remained constant to the two types of shafts, in order to unify the evaluation criteria.

\subsection{Mechanical Characterization}

Bending tests were carried out on the shafts manufactured using FDM, following the ASTM D790 technical standard. Five specimens were tested as required by the standard, at a deformation rate of $1 \mathrm{~mm} / \mathrm{min}$ and with a load of $12 \mathrm{KN}$

\section{Results and Discussion}

Results of maximum strength, maximum deformation and Young's modulus obtained for each type of specimen are shown in Table 3.
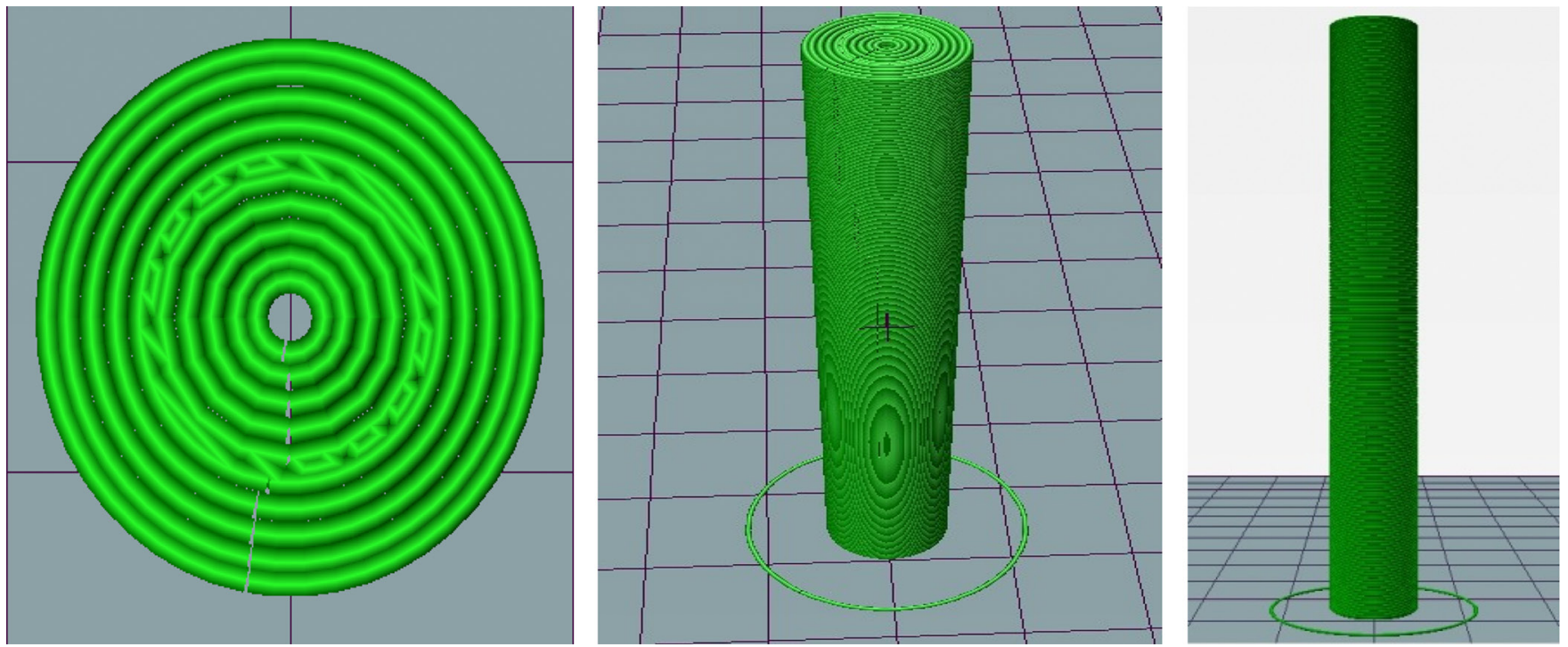

Figure 2. Layers' location regarding the inclination angle of $\alpha$ and $\beta$.
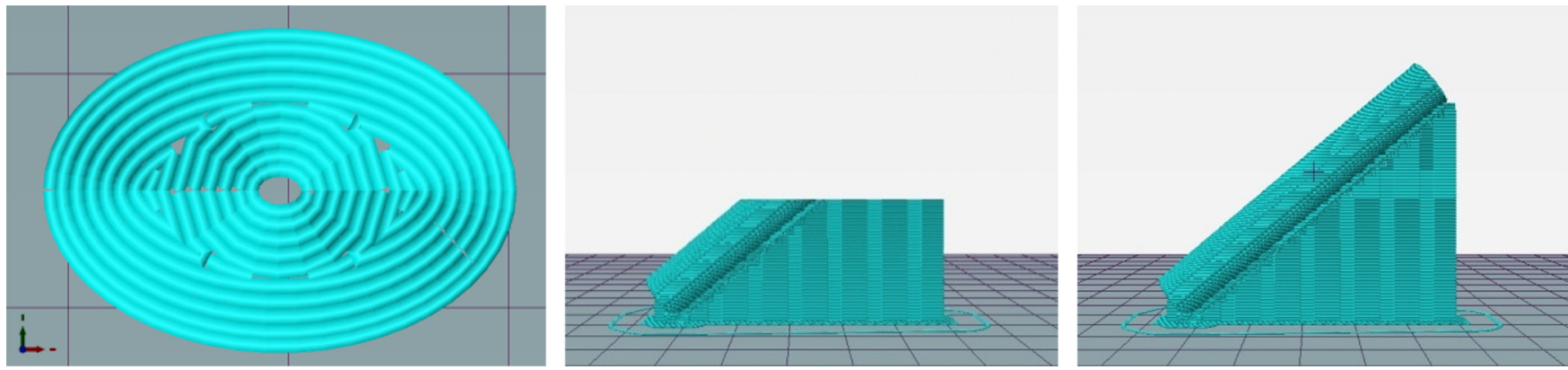

Figure 3. Shaft projections manufactured with a $\alpha$ angle. 
Table 3. Flexion test results

\begin{tabular}{|l|c|c|c|}
\hline \multicolumn{1}{|c|}{ System } & $\begin{array}{c}\text { Module } \\
(\mathrm{GPa})\end{array}$ & Strengt (MPa) & Deformatio (\%) \\
\hline PLA $0^{\circ}$ & $0,6 \pm 0,4$ & $33,8 \pm 5,9$ & $3,1 \pm 1$ \\
\hline PLA $50^{\circ}$ & $1,1 \pm 0,2$ & $46,1 \pm 4,2$ & $4,6 \pm 0,8$ \\
\hline PLA $50^{\circ} \mathrm{T}$ & $1,2 \pm 0,2$ & $54,4 \pm 10,7$ & $5,7 \pm 2,3$ \\
\hline
\end{tabular}

Exemplars manufactured in vertical deposition were called PLA $0^{\circ}$. It should be noted that for the anisotropy of the pieces with inclination of PLA $50^{\circ}$, tests were carried out with two different orientations. The first orientation of PLA $50^{\circ}$ was made according to the application angle concerning the load, as seen in the free-body diagram of Figure 8.

In the second orientation, called PLA $50^{\circ} \mathrm{T}$ (transverse), the specimen was rotated 90 degrees in relation to the neutral axis, in this case layers formed a geometry similar to that produced in a weld bead and are misaligned with regards to the load as shown in Figure 11.

Analyzing the results of each configuration, it is detectable that PLA $50^{\circ} \mathrm{T}$ is the system that reaches the highest values of up to 54.4, MPa flexural strength. Authors such as $\frac{14,15}{15}$ agree that the printing parameters such as speed, layer height, temperature, orientation, among others, influence resistance.

For the evaluated systems, the only parameter that was modified was the inclination of layers, therefore, it can be said that manufacturing with the raised conditions contributes to the strength of the pieces, since a greater effort of $61 \%$ is obtained. Figure 4 shows a graph detailing Stress $v s$ Strain of the 3 configurations.

According to the previous diagram, the shafts' behaviour to bending is of elastic-linear character in the

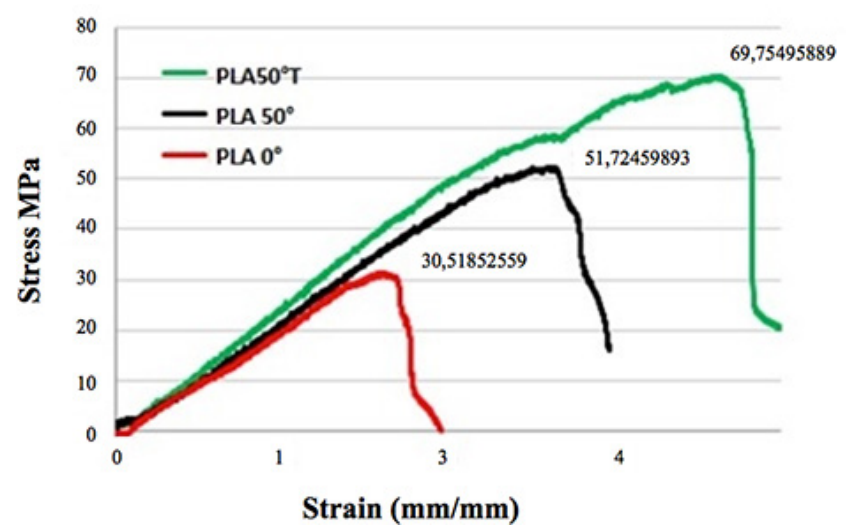

Figure 4. Top and frontal projections of the Shaft Manufactured with a $\beta$ angle. three systems, caused by the fragile behaviour of PLA. In this sense, it can be noted that PLA $50^{\circ}$ transversal system has the best behaviour regarding mechanical properties, as observed in the slope's elastic zone that represents Young's modulus. On the other hand, maximum strength increases considerably respecting other configurations. It is important to consider that disposition of $50^{\circ}$ transversal PLA presents the highest percentage of deformation, which indicates that the material presents a certain degree of plasticity in its layer distribution.

According to the previous results, it is evidenced that the PLA $0^{\circ}$ configuration generates pure tension stress below its central line (neutral axis) this directly affects the bonding surface of the layers and consequently these tend to separate causing a clean break in the shaft. In this case, failure occurs due to the separation of layers, not from the rupture of the material. See the diagram in Figure 5.

According to the Fractography technique $\frac{16}{6}$ the fracture produced in exemplar PLA $0^{\circ}$ is of fragile nature. In Figure 6a, clean fracture is noted with a fault line that follows the same direction as the load applied. In Figure $6 \mathrm{~b}$, it is observed that the pores generated in the failure zone are small, this occurs with materials that do not

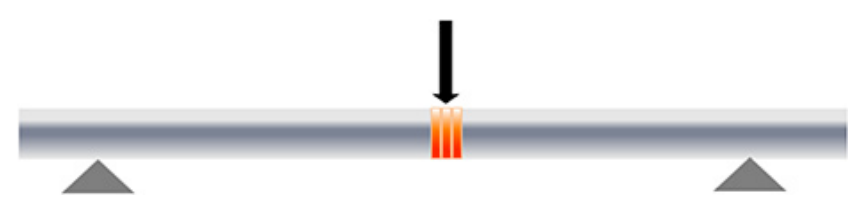

Figure 5. Vertical specimen free-body diagram.

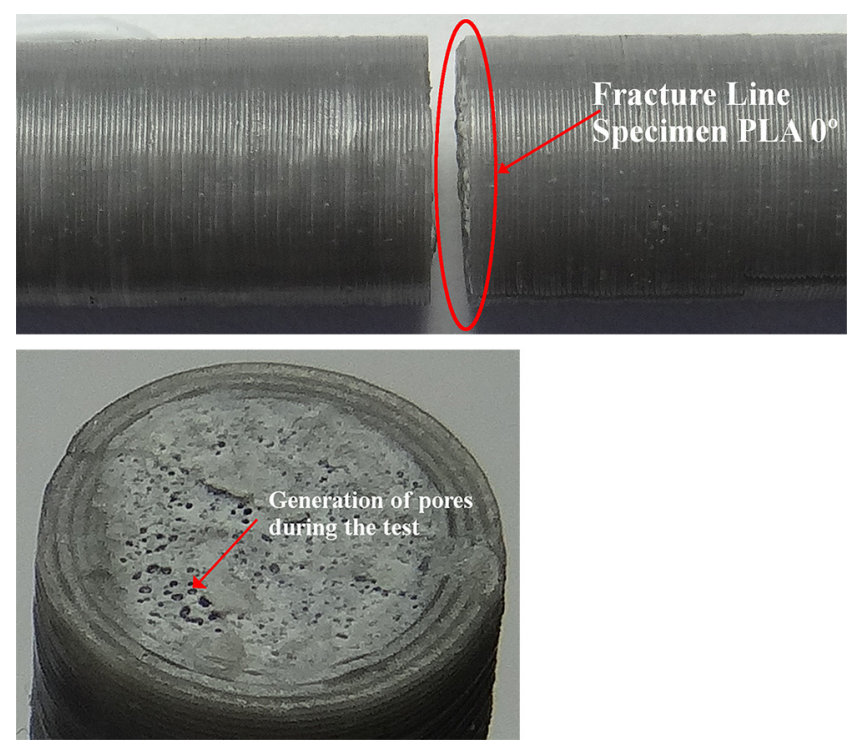

Figure 6. Failure of PLA $0^{\circ}$ specimen. 
present major deformations before fracture. In addition, analyzing the stress-strain graph of PLA $0^{\circ}$, it is clear that elongation of the test piece before fracture does not exceed $2 \%$ which, according to the normative, corresponds to fragile materials.

In the second case, layers of the specimen have an inclination of $50^{\circ}$ with respect to exertion, as mentioned above, the origin of the fracture moves according to the point on which the load is applied, delaying the fault's appearance (Figure 7).

The fault's behaviour is similar to that in the previous case, the fracture follows the direction of inclination of the layer as seen in Figure 8a, but the strength required to break the specimen is 1.36 times greater than that of PLA $0^{\circ}$. A possible cause for the fault can be attributed to the fact that the union area between layers is greater, allowing them to form ellipses internally rather than concentric circles, thus generating greater adherence. The phenomenon of breakage is analyzed as a positive factor for the manufacture of elements using 3D printing, as a consequence, the deposition lines' inclination regarding

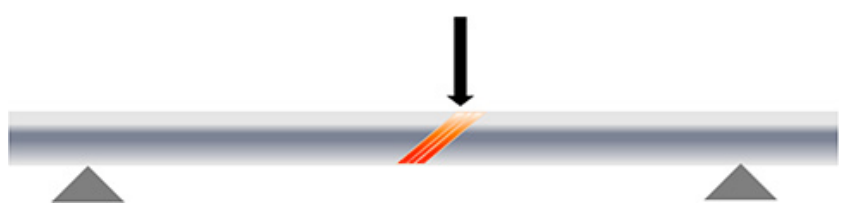

Figure 7. PLA50 ${ }^{\circ}$ specimen free-body diagram.
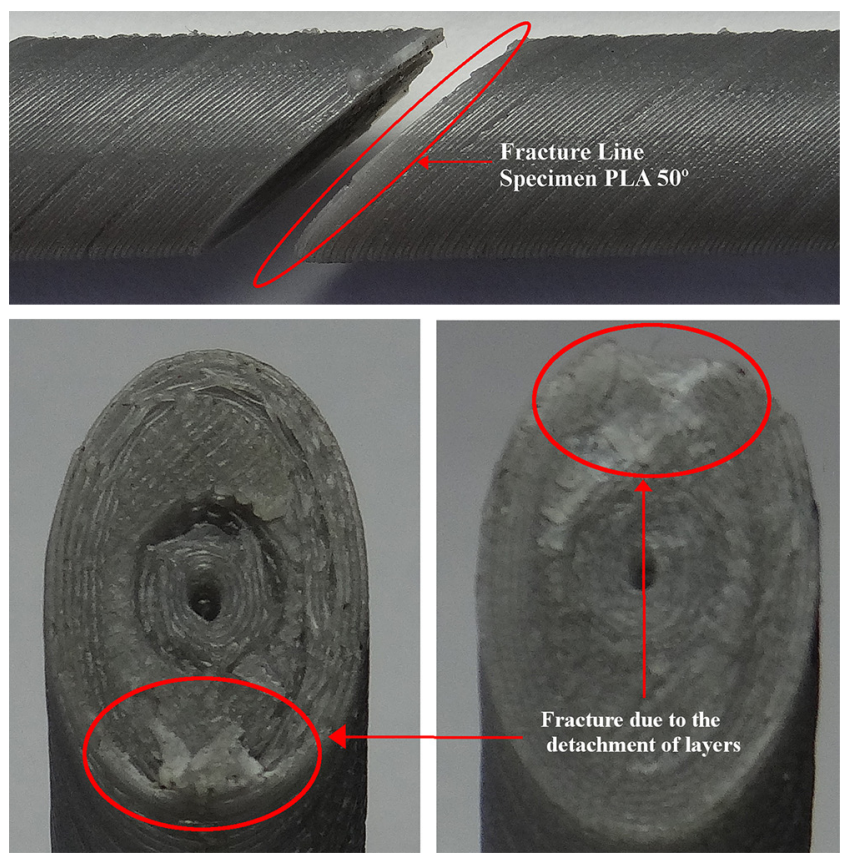

Figure 8. Failure of PLA $50^{\circ}$ specimen. the load causes delay of the material's failure and therefore increases its ductility.

In the following study, the PLA $50^{\circ}$ test piece, received a modification respecting the load's application, for this purpose it was turned to $90^{\circ}$ regarding the neutral axis, consequently, layers do not have a defined alignment concerning load as seen in the free-body diagram of Figure 9.

On this occasion, the layers' orientation makes the fault's origin difficult, comparing it to specimen PLA $0^{\circ}$, it can be noted that a strength 1.6 times greater is required to cause rupture. In Figure 11a it is displayed that the fault line does not have a defined orientation, therefore, in Figure 10b, cavities with greater depths and diameters than in the previous cases are noted in the fault's area. According to images of fractography, it is evident that before the fracture there was a deformation of the specimen, consequently, an increase in the percentage of elongation can be deduced.

The increase in ductility is reflected in the results obtained in the values deformation percentage, see Figure 11 , the increase corresponds to $123 \%$ between the PLA $50^{\circ}$ transversal and the PLA $0^{\circ}$. These results validate

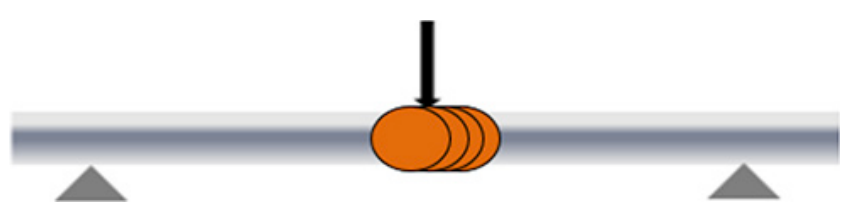

Figure 9. PLA $50^{\circ}$ Transversal specimen free-body diagram.
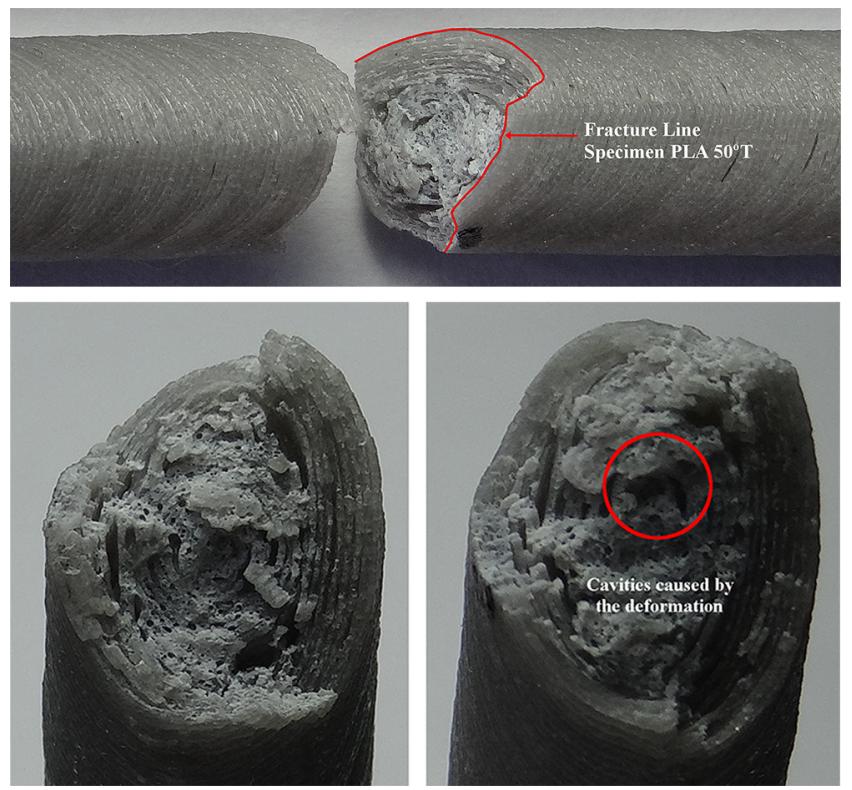

Figure 10. Failure of PLA $50^{\circ}$ transversal specimen. 


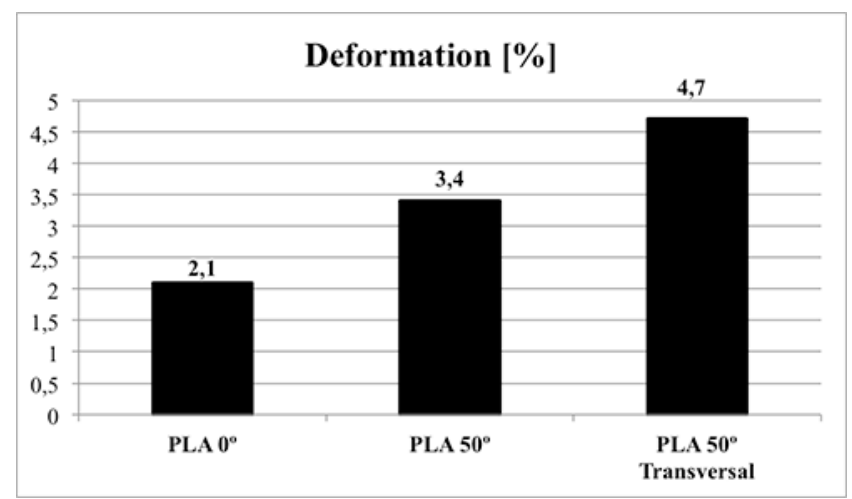

Figure 11. Deformation percentage values for different configurations comparison.

the theory of inclination's influence of deposition lines respecting applied load, which is of great importance to the design and manufacture of parts fabricated using FDM.

\section{Conclusions}

In this investigation, the behaviour of the flexural mechanical properties was evaluated by means of modification of printing parameters, mainly orientation of the deposition lines and the load's application position.

According to the results of mechanical flexural properties, variations in the tests' calculated parameters are evidenced as a result of the anisotropic nature that generates the deposition's assembly orientation in the direction of the applied force.

The failure analysis of the cylindrical shafts by means of fractography shows important characteristics in correspondence to applied load, mainly due to the increase of ductility in PLA $50^{\circ}$ system, as a consequence of energy absorption by the material from the beginning and spreading of the crack.

\section{References}

1. Silva JRC, Fonseca GFG, Andrade MM. Ensaios Mecânicos Em Elastômeros Termoplásticos Utilizados EmImpressoras 3D Para a Construção De Próteses De Mão. In: Congresso - Pan American Health Care Exchanges (PAHCE), Brasília. Conference CD Version. México - D.F; 2014. p. 44-49.

2. Weng Z, Wang J, Senthil T, Wu L. Mechanical and thermal properties of $\mathrm{ABS} /$ montmorillonite nanocomposites for fused deposition modeling 3D printing, Materials and
Design. 2016; 102:276-83. https://doi.org/10.1016/j.matdes. 2016.04.045.

3. Lanaro M, Forrestal DP, Scheurer S, Slinger DJ, Liao S, Powell SK. 3D printing complex chocolate objects: Platform design, optimization and evaluation, Journal of Food Engineering. 2017; 215:13-22. https://doi.org/10.1016/j. jfoodeng.2017.06.029.

4. Lille M, Nurmela A, Nordlund E, Metsä-Kortelainen S, Sozer N. Applicability of protein and fiber-rich food materials in extrusion-based $3 \mathrm{D}$ printing, Journal of Food Engineering. 2018: 220:20-7. https://doi.org/10.1016/j. jfoodeng.2017.04.034.

5. Hasiuk FJ, Harding C, Renner AR, Winer E. TouchTerrain: A simple web-tool for creating 3D-printable topographic models, Computers and Geosciences. 2017; 109:25-31. https://doi.org/10.1016/j.cageo.2017.07.005.

6. Abdullah AM, Noraihan T, Tuan Rahim A, Mohamad D, Akil HM, Rajion ZA. Mechanical and physical properties of highly ZrO 2/ $\beta$-TCP filled polyamide 12 prepared via fused deposition modelling (FDM) 3D printer for potential craniofacial reconstruction application, Materials Letters. 2017; 189:307-9. https://doi.org/10.1016/j.matlet. 2016.11.052.

7. Rogers LS, Van Wert JC, Mensinger AF. An implantable two axis micromanipulator made with a $3 \mathrm{D}$ printer for recording neural activity in free-swimming fish, Journal of Neuroscience Methods. 2017; 288:29-33. https://doi. org/10.1016/j.jneumeth.2017.06.012. PMid: 28648718.

8. Pohl BM, Gasca F, Christ O, Hofmann UG. 3D printers may reduce animal numbers to train neuroengineering procedures. 6th International IEEE/EMBS Conference on Neural Engineering (NER); 2013. p. 887-90.

9. Borjas R, Flores W. Developing a human prosthesis using a $3 \mathrm{D}$ printer in Honduras. IEEE Thirty Fifth Central American and Panama Convention; 2015. p. 1-5.

10. Rodriguez E, Cortés E, Pe-a C. Application of the Qfd Methodology in the Development of a 3d Printer, Revista Colombiana de Tecnologías de Avanzada. 2016; 2:1-8.

11. Dizon JRC, Espera AH, Chen Q, Advincula RC. Mechanical characterization of 3D-printed polymers, Additive Manufacturing. 2018; 20:44-67. https://doi.org/10.1016/j.addma. 2017.12.002.

12. Fernandez-Vicente M, Calle W, Ferrandiz S, Conejero A. Effect of Infill Parameters on Tensile Mechanical Behavior in Desktop 3D Printing, 3D Print Additive Manufacturing. 2016; 3(3):183-92.

13. Alberto LA. Correlaciones Procesado-estructura propiedades ensistemas poliméricos complejos basados en poliesteres biodegradables. Evaluación de su possible uso en aplicaciones ecológicas y biomédicas. PhD thesis, UPV/EHU; 2008. 
14. Abbott AC, Tandon GP, Bradford RL, Koerner H, Baur JW. Process-structure-property effects on ABS bond strength in fused filament fabrication, Additive Manufacturing. 2018; 19:29-38. https://doi.org/10.1016/j. addma.2017.11.002.

15. Croccolo D, De Agostinis M, Olmi G. Experimental characterization and analytical modelling of the mechanical behaviour of fused deposition processed parts made of ABS-M30, Computational Materials Science. 2013; 79: 506-18. https://doi.org/10.1016/j.commatsci.2013.06.041.

16. Ipohorski M, Acuna RJ. Fractografia Aplicacion Análisis de falla. Comisión Nacional de Energía Atómica; 1988. p. 180. 